\title{
A case of refeeding syndrome during intradialytic parenteral nutrition
}

\author{
Yoshihisa Miyamoto ${ }^{1,2}$, Yoshifumi Hamasaki $^{1,2^{*}}$, Akihiko Matsumoto ${ }^{1}$, Kent Doi ${ }^{3}$ and Masaomi Nangaku ${ }^{1,2}$
}

\begin{abstract}
Background: Refeeding syndrome is a potentially fatal electrolyte shift in patients with rapid feeding after low-calorie intake. Although the key to diagnosing refeeding syndrome is hypophosphatemia after feeding, renal dysfunction might hide refeeding hypophosphatemia, especially in maintenance hemodialysis patients. Intradialytic parenteral nutrition (IDPN) is a therapeutic approach used to treat malnourished patients with maintenance hemodialysis. No earlier report describes a study of refeeding syndrome complicated with IDPN.

Case presentation: We present a case of a 77-year-old man undergoing maintenance hemodialysis for 17 years. While IDPN was administered after 10 days fasting, ventricular tachycardia (VT) occurred, possibly because of a rapid intracellular shift of potassium mainly explained as refeeding syndrome in addition to potassium removal by hemodialysis. A greater decline of serum phosphate concentrations during hemodialysis on that day compared with that during usual hemodialysis session supports our inference of the contribution of refeeding syndrome to VT complicated with hypokalemia.

Conclusion: Physicians should know that IDPN can induce refeeding hypophosphatemia and rapid intracellular shift of potassium. Synergic lowering effects of serum potassium both with intracellular shift caused by refeeding syndrome and potassium removal by hemodialysis might cause lethal arrhythmia in patients treated with IDPN. Before treating malnourished patients with IDPN, the risk of refeeding syndrome should be assessed in patients with high risk of refeeding syndrome.
\end{abstract}

Keywords: Hemodialysis, Intradialytic parenteral nutrition (IDPN), Refeeding hypophosphatemia, Ventricular tachycardia

\section{Background}

Refeeding syndrome entails dynamic metabolic changes including potentially fatal electrolyte shift in patients with rapid feeding after low-calorie intake [1]. Metabolic changes include hypophosphatemia, hypokalemia, hypomagnesemia, sodium retention, and hyperglycemia [2]. Although hypophosphatemia is a hallmark of refeeding syndrome, renal dysfunction might hide refeeding hypophosphatemia, especially in maintenance hemodialysis patients [3]. For preventing refeeding syndrome, we should slowly start nutritional repletion of energy and monitor electrolyte levels [1].

\footnotetext{
*Correspondence: yhamasaki-tky@umin.ac.jp

'Department of Hemodialysis and Apheresis, The University of Tokyo Hospital, Tokyo, Japan

${ }^{2}$ Division of Nephrology and Endocrinology, The University of Tokyo, Tokyo, Japan

Full list of author information is available at the end of the article
}

Malnutrition is a common and crucially important problem in patients with maintenance hemodialysis. Its prevalence is $23-73 \%$ [4], depending on the selected nutritional markers and the population studied. Intradialytic parenteral nutrition (IDPN) is a therapeutic approach to treating malnourished patients with maintenance hemodialysis [4].

\section{Case presentation}

A 77-year-old anuric man receiving hemodialysis (HD) for 17 years was admitted to our hospital because of severe anemia caused by diverticular hemorrhage. His past medical history included diverticular hemorrhage, sigmoid colonic carcinoma treated with endoscopic mucosal resection, and prostate carcinoma. All of his medications, including calcium carbonate, lanthanum carbonate hydrate, alphacalcitriol, and cinacalcet, were stopped immediately after admission. He was treated with bowel rest and red cell concentrate transfusion. His blood stool improved gradually

(c) The Author(s). 2018 Open Access This article is distributed under the terms of the Creative Commons Attribution 4.0 International License (http://creativecommons.org/licenses/by/4.0/), which permits unrestricted use, distribution, and 
over 6 days. Intravenous peripheral infusion was continued during his bowel rest for 10 days. The administered intravenous fluid contained $26 \mathrm{~g}$ of glucose, $100 \mathrm{mg}$ of thiamine, $100 \mathrm{mg}$ of pyridoxine, and $1 \mathrm{mg}$ of cyanocobalamin in $1000 \mathrm{~mL}$ of half saline per day. The patient had neither oral nor intravenous potassium supplementation during 10 days of fasting. During hospitalization, he received three sessions of 4-h HD per week under the dialysis condition of $230 \mathrm{~mL} / \mathrm{min}$ blood flow rate, $500 \mathrm{~mL} / \mathrm{min}$ dialysate flow rate, and $2.1-\mathrm{m}^{2}$ surface area of dialyzer membrane: the same as that he received at an outpatient clinic before admission. Concentrations of dialysate electrolytes were $140 \mathrm{mEq} / \mathrm{L}$ sodium, $2.0 \mathrm{mEq} / \mathrm{L}$ potassium, $3.0 \mathrm{mEq} / \mathrm{L}$ calcium, and $35 \mathrm{mEq} / \mathrm{L} \mathrm{HCO}_{3}{ }^{-}$. Potassium concentrations before dialysis were $5.6 \mathrm{mEq} / \mathrm{L}, 4.9 \mathrm{mEq} / \mathrm{L}$, and $4.4 \mathrm{mEq} / \mathrm{L}$, respectively, on the third, sixth, and eighth days after admission. His dry weight was $54.9 \mathrm{~kg}$; his body mass index (BMI) was $20.3 \mathrm{~kg} / \mathrm{m}^{2}$.

On the 10th day after admission, IDPN was started during each HD session because of prolonged fasting. IDPN fluid consisting of a mix of $200 \mathrm{~mL}$ of $50 \%(w / w)$ glucose, $200 \mathrm{~mL}$ of $7.2 \%$ amino acid solution, and $250 \mathrm{~mL}$ of $20 \%(w / w)$ fat emulsions was administered to the patient through the venous chamber of the dialysis circuit at the rate of $160 \mathrm{~mL} / \mathrm{h}$. The total and administration rate of calories of IDPN were, respectively, approximately $970 \mathrm{kcal}$ and $240 \mathrm{kcal} / \mathrm{h}$. Non-sustained ventricular tachycardia (VT) occurred about one and half hours after starting HD. At that time, the net amount of the infused IDPN fluid was approximately $40 \%$ of the prepared fluid $(390 \mathrm{kcal})$. The plasma potassium concentration was $3.2 \mathrm{mEq} / \mathrm{L}$. It was considered that the VT was triggered by the rapid fall of serum potassium level which resulted from intracellular shift by refeeding syndrome in addition to removal by HD. Other symptoms characteristics of refeeding syndrome, such as heart failure, rhabdomyolysis, convulsion, and hemolytic anemia, were not observed. Therefore, we stopped the administration of IDPN immediately and adjusted the potassium concentration of dialysate to
$4.0 \mathrm{mEq} / \mathrm{L}$. After the HD session, the serum potassium concentration was $3.7 \mathrm{mEq} / \mathrm{L}$. Although pre-dialytic BUN of the 10th day of admission was lower than that at 1 month before admission $(28.9 \mathrm{mg} / \mathrm{dL}$ vs. $72.1 \mathrm{mg} / \mathrm{dL})$, $\mathrm{Kt} / \mathrm{V}$ was quite similar (1.69 vs. 1.69). His serum phosphate level was decreased substantially from 7.3 to $1.9 \mathrm{mg} / \mathrm{dL}$ during the HD session on the 10th day of admission, although it was decreased from 6.1 to $2.2 \mathrm{mg} / \mathrm{dL}$ during an HD session, 6 weeks before admission (Table 1). From 12-lead electrocardiography conducted immediately after the VT, results demonstrated that the corrected QT interval (QTc) was prolonged compared with his baseline $(0.513 \mathrm{~s}$ vs. $0.476 \mathrm{~s})$. Just after the HD session on the 10th day, $10 \mathrm{mmol}$ of sodium phosphate and $20 \mathrm{mEq}$ of magnesium sulfate were supplemented intravenously. Additional magnesium was supplemented because VT recurred once approximately $10 \mathrm{~h}$ after the HD session. From the 11th day after admission, oral nutrient intake was re-started. The amount of oral nutritional intake was increased gradually. Just before the next HD session on the 13th day of admission, his serum phosphate concentration was $4.6 \mathrm{mg} / \mathrm{dL}$. On the 14th day after admission, only $75 \%$ stenosis of the right coronary artery (posterior descending artery) was shown by coronary angiography. It was not regarded as a cause of his arrhythmia. From the 11th day after admission, VT was never observed on continuous ECG monitoring. On the 16th day after admission, he was discharged. He then returned home.

\section{Indication for IDPN}

IDPN is a method of parenteral nutrition through the venous drip chamber of the hemodialysis circuit used while the patient was receiving hemodialysis [5]. IDPN has been proposed to improve the nutritional status of malnourished patients on chronic hemodialysis. Some guidelines refer to indication of IDPN. Table 2 presents the IDPN indication criteria suggested in the representative guidelines: the British Columbia Renal Agency (BC

Table 1 Serum potassium and phosphate level 6 weeks before admission and post-admission day 10

\begin{tabular}{|c|c|c|c|c|c|c|c|}
\hline & \multicolumn{2}{|c|}{6 weeks before admission } & \multirow{2}{*}{$\begin{array}{l}\text { Post-admission day } 3 \\
\text { (first session after } \\
\text { admission) } \\
\text { Pre-HD }\end{array}$} & \multicolumn{2}{|c|}{ Post-admission day 10} & \multicolumn{2}{|c|}{ Post-admission day 13} \\
\hline & Pre-HD & Post-HD & & Pre-HD & Post-HD & Pre-HD & Post-HD \\
\hline Hemoglobin (g/dL) & 11.9 & 13.0 & 9.8 & 10.5 & NA & 10.2 & NA \\
\hline Potassium (mEq/L) & 5.3 & 3.8 & 5.6 & 3.8 & 3.7 & 4.5 & 3.6 \\
\hline Phosphate (mg/dL) & 6.1 & 2.2 & NA & 7.3 & 1.9 & 4.6 & 1.6 \\
\hline Calcium (mg/dL) & 8.1 & 9.9 & NA & 8.1 & 8.5 & 8.5 & 9.0 \\
\hline Magnesium (mg/dL) & NA & NA & NA & NA & 1.7 & 2.4 & NA \\
\hline Albumin (g/dL) & 3.5 & NA & 3.2 & 3.0 & NA & 2.9 & NA \\
\hline
\end{tabular}

Pre-HD and post-HD respectively denote laboratory data obtained before and after hemodialysis $N A$ not available 
Table 2 Indication criteria of IDPN proposed in guidelines

\begin{tabular}{|c|c|c|c|}
\hline & BC Renal Agency 2007, updated in 2014 & The German Society of Nutrition 2009 & $\begin{array}{l}\text { European Best Practice } \\
\text { Guidelines on } \\
\text { hemodialysis from } \\
\text { ERA-EDTA } 2007\end{array}$ \\
\hline Serum albumin & 3-month average $<3.4 \mathrm{~g} / \mathrm{dL}$ & 3-month average $<3.4 \mathrm{~g} / \mathrm{dL}$ & \\
\hline Weight loss & $>10 \%$ of IBW or UBW & $>10 \%$ of IBW or $20 \%$ of UBW & \\
\hline SGA & $\mathrm{B}$ or $\mathrm{C}$ indicating moderate to severe malnutrition & $\mathrm{C}$ indicating severe malnutrition & \\
\hline Oral protein intake & $<1.0 \mathrm{~g} / \mathrm{kg}$ & $<0.8 \mathrm{~g} / \mathrm{kg}$ & $>0.8 \mathrm{~g}$ protein $/ \mathrm{kg} \mathrm{IBW}$ \\
\hline Oral calories intake & $<25 \mathrm{kcal} / \mathrm{kg}$, can take $\geq 50 \%$ of needs orally & $<25 \mathrm{kcal} / \mathrm{kg}$ & $>20 \mathrm{kcal} / \mathrm{kg} \mathrm{IBW}$ \\
\hline Others & Documented diagnosis of a gastrointestinal disorder & $\begin{array}{l}\text { 3-month rolling average predialysis } \\
\text { serum creatinine }<8.0 \mathrm{mg} / \mathrm{dL}\end{array}$ & \\
\hline
\end{tabular}

BC Renal Agency, British Columbia Renal Agency, ERA-EDTA European Renal Association-European Dialysis and Transplant Association, IBW ideal body weight, SGA subjective global assessment, UBW usual body weight

Renal Agency) [5], European Renal Association-European Dialysis and Transplant Association (ERA-EDTA) [6], and the German Society of Nutrition [7]. These guidelines recommend that nutritional assessments be done using serum albumin, weight loss, subjective global assessment (SGA), oral protein and calorie intake, and so on for defining malnutrition. Most indication criteria of IDPN overlap those of protein-energy wasting (PEW) proposed by the International Society of Renal Nutrition and Metabolism (ISRNM) in 2008 [8]. Before considering IDPN, these guidelines above emphasize that clinicians should deal with underlying causes of malnutrition and then attempt to increase patients' oral intake with oral nutritional supplements including tube feeding. IDPN is a treatment option for malnourished patients only when these attempts have failed. Moreover, BC Renal Agency and ERA-EDTA state that patients receiving IDPN should have some oral intake: patients can take over $50 \%$ of caloric needs in $\mathrm{BC}$ Renal Agency guideline and greater than $0.8 \mathrm{~g}$ protein $/ \mathrm{kg}$ ideal body weight (IBW) and greater than $20 \mathrm{kcal} / \mathrm{kg} \mathrm{IBW}$ in the European Best Practice Guidelines (EBPG). The guidelines imply that patients who have little or no oral intake are not candidates for IDPN, therefore meaning that IDPN is not recommended for patients with high risk of refeeding syndrome. Actually, the BC Renal Agency guideline states the potential metabolic complications of IDPN which include electrolyte abnormalities associated with refeeding and recommends routine monitoring of potassium, magnesium, and phosphorus.

\section{Efficacy of IDPN}

Although the indication of IDPN in malnourished hemo dialysis patients is demonstrated, little is known about the benefits of IDPN, especially in terms of mortality and morbidity (e.g., infectious complications, hospitalization). Although several reports of the relevant literature describe randomized controlled trials that have been conducted to evaluate the efficacy of IDPN $[9,10]$, only the French Intradialytic Nutrition Evaluation Study (FineS) evaluated the effects of IDPN on mortality [9]. The left column of Table 3 presents a summary of FineS. FineS compared two treatment arms: oral nutritional supplements with

Table 3 Representative randomized controlled trials for IDPN

\begin{tabular}{lll}
\hline & FineS trial 2007 & German IDPN trial 2017 \\
\hline Inclusion criteria & & \\
Age & $18-80$ years old & $>18$ years old \\
Hemodialysis vintage & $>6$ months & $>6$ months \\
BMI & $<20 \mathrm{~kg} / \mathrm{m}^{2}$ & \\
BW loss within 6 months & $>10 \%$ & $<3.5 \mathrm{~g} / \mathrm{dL}$ \\
Serum albumin & $<3.5 \mathrm{~g} / \mathrm{dL}$ & $<25 \mathrm{mg} / \mathrm{dL}$ \\
Serum prealbumin & $<30 \mathrm{mg} / \mathrm{dL}$ & B or C \\
SGA & & IDPN (3 times per week) with standardized nutritional \\
Exposure & IDPN with oral nutritional supplements & counseling over 16 weeks \\
& for 1 year & Standardized nutritional counseling only \\
Comparison & Oral nutritional supplements only & IDPN significantly increased prealbumin (changes in \\
Outcome & IDPN did not have additional benefit on & serum prealbumin from baseline to week 16) $(p=0.02)$
\end{tabular}


and without IDPN. In FineS, unfortunately, the addition of IDPN did not improve the 2-year patient survival. In fact, the execution of FineS included several factors that might have reduced the benefits of IDPN. First, the sample size in the study was small. Secondly, both arms were intervened with oral supplement and demonstrated improved BMI, serum albumin, and prealbumin from baseline. Therefore, it was considered that FineS was underpowered to detect additional effects of IDPN on mortality. Nonetheless, FineS elucidated serum prealbumin increase $>30 \mathrm{mg} / \mathrm{L}$ during the first 3 months after starting nutritional treatment as an independent prognostic factor.

After FineS, the German IDPN-Trial group conducted a randomized trial to investigate the impact of IDPN to the changes of serum prealbumin [10]. Maintenance hemodialysis patients with PEW were assigned randomly to two groups with or without IDPN in addition to standardized nutritional counseling over 16 weeks. In the full analysis set consisting of 83 patients, the mean increase in serum prealbumin after 16 weeks was $26.31 \mathrm{mg} / \mathrm{L} \mathrm{(} \pm$ $58.66 \mathrm{mg} / \mathrm{L}$ ) in the 39 patients receiving IDPN compared with a decrease of $1.84 \mathrm{mg} / \mathrm{L}( \pm 49.35 \mathrm{mg} / \mathrm{L})$ in the $44 \mathrm{pa}-$ tients of the control group $(p=0.02)$. Results show that the German IDPN-Trial group revealed the efficacy of IDPN for improvement of nutritional status and that IDPN might improve prognosis of patients with malnutrition.

\section{Diagnosis of refeeding syndrome}

Refeeding syndrome is a potentially fatal electrolyte shift in patients with rapid feeding after low-calorie intake. Classically clinical features of refeeding syndrome include salt and water retention, hypokalemia caused by rapid cellular uptake of potassium as glucose and amino acids taken up during cellular synthesis (state of anabolism), hypophosphatemia because of increased phosphorylation of glucose, rapid depletion of thiamine, and hypomagnesemia caused by cellular uptake [11]. As consequences of these metabolic abnormalities, multi-organ complications such as heart failure, arrhythmia, respiratory failure, and Wernicke's encephalopathy can occur and cause death. Although Rio et al. proposed diagnostic criteria [12], it is difficult to define refeeding syndrome precisely because of the wide spectrum of the clinical entity of refeeding syndrome, extending from asymptomatic chemical abnormalities to life-threatening conditions. From this viewpoint, Stanga et al. proposed the two distinguishing concepts of symptomatic refeeding syndrome and potential or biochemical refeeding syndrome [11]. One diagnostic criterion presented by Rio et al. above requires fulfillment of three features: (1) electrolyte abnormalities including severe hypokalemia $(<2.5 \mathrm{mmol} / \mathrm{L})$, hypophosphatemia $(<0.32 \mathrm{mmol} / \mathrm{L}$, i.e., $<1.0 \mathrm{mg} / \mathrm{dL})$, and hypomagnesemia ( $<0.5 \mathrm{mmol} / \mathrm{L}$, i.e., $<1.2 \mathrm{mg} / \mathrm{dL})$; (2) peripheral edema or acute circulatory fluid overload; and (3) disturbance of organ function including cardiac failure and pulmonary edema. Rio's criteria are regarded as symptomatic refeeding syndrome in Stanga's review. By contrast, using a potential or biochemical refeeding syndrome, physicians would be expected to detect early signs of refeeding syndrome and act without delay to prevent emergence of the symptomatic features. Some nutritional studies related to preventing refeeding syndrome or early intervention against refeeding syndrome employ hypophosphatemia as an inclusion criterion: "refeeding hypophosphatemia" [13, 14]. The cutoff of serum phosphate concentration for hypophosphatemia in these studies were $<0.65 \mathrm{mmol} / \mathrm{L}$ $(<2.0 \mathrm{mg} / \mathrm{dL})$, although the cutoff was determined arbitrarily. As De Silva et al. pointed out, renal dysfunction might hide refeeding hypophosphatemia. Refeeding hypophosphatemia might be underdiagnosed because baseline serum phosphates are higher in some patients requiring renal replacement therapy or with acute kidney injury (AKI)/chronic kidney disease (CKD) than in the general population [3].

It is noteworthy that the guidelines [5-7] presented in our earlier chapter do not indicate details of a diagnostic definition of refeeding syndrome or "relative" hypophosphatemia specifically in hemodialysis patients. Nor do they explain risk assessment of refeeding syndrome before IDPN starts.

\section{Prevention and treatment of refeeding syndrome}

For prevention and treatment of refeeding syndrome, clinicians should always assess the risk of developing refeeding syndrome when considering starting nutritional support. The National Institute for Health and Care Excellence (NICE) guideline in 2006 introduced the criteria to identify patients at high risk of developing refeeding problems [15]. The criteria consist of the body mass index (BMI), the degree of weight loss, duration of little or no nutritional intake, and other risk factors of refeeding syndrome: history of diuretics, chemotherapy, antacids, and alcohol or drug abuse, including insulin. Similarly, the Irish Society for Clinical Nutrition and Metabolism (IrSPEN) guidelines in 2013 provided criteria for the identification of patients at risk of refeeding syndrome $[14,16]$. They presented three categories based on risk factors: moderate, high, and extremely high. It is noteworthy that both guidelines suggest only 5 days of little or no nutritional intake as a risk factor of refeeding syndrome. Some earlier reports have described lower prealbumin before nutritional support as a predictor of refeeding syndrome [17]. Measurement of prealbumin before nutritional support can facilitate the prediction of refeeding syndrome.

Purhassan et al. used NICE criteria to investigate the share of patients at risk of refeeding syndrome in the 
geriatric acute care ward [15]. They reported $69.9 \%$ of geriatric hospitalized patients (mean age of $83.1 \pm$ 6.8 years) at risk of refeeding syndrome. One must be aware that "refeeding syndrome at risk" is common especially in elderly patients. One should meticulously assess the risk of refeeding syndrome before nutritional support.

The speed of nutritional administration is an important factor associated with the incidence of refeeding syndrome. Guidelines published by IrSPEN demonstrate how clinicians initially adjust the speed of nutrition support according to the concrete risk stratification [18]: $20 \mathrm{kcal} / \mathrm{kg} /$ day for moderate risk, $10 \mathrm{kcal} / \mathrm{kg} /$ day for high risk, and $5 \mathrm{kcal} / \mathrm{kg} /$ day for extreme high risk. NICE guidelines recommend the increase of levels slowly to meet full needs by 4-7 days or sooner [15].

After starting nutritional administration, monitoring and management of electrolyte abnormalities should be maintained over subsequent days. After starting feeding with sufficient thiamine supplements, serum electrolytes and especially phosphorus should be monitored closely to detect biochemical refeeding syndrome before fatal complications such as cardiovascular collapse develop. Appropriate and prompt supplementation of deficient electrolytes should be done according to serum concentrations. In patients at extremely high risk, monitoring cardiac rhythm continuously is recommended in these guidelines [13].

Management of hypophosphatemia because of refeeding syndrome is often necessary. Intravenous replacement of phosphate is performed in general. The Refeeding Syndrome Trial Investigators Group conducted a randomized controlled trial in an ICU setting for a caloric strategy during the management of refeeding syndrome: serum phosphate concentration decreased to less than $0.65 \mathrm{mmol} / \mathrm{L}(2.0 \mathrm{mg} / \mathrm{dL})$ within $72 \mathrm{~h}$ after starting nutritional support [19]. Patients with refeeding hypophosphatemia were divided into two groups: reduced and non-reduced caloric intake groups. Although phosphate supplementation was conducted for both groups, caloric intake restriction improved patient survival significantly at day 60 (91\% vs. $78 \%)$. The authors suggested caloric restriction as a therapeutic option for critically ill patients who develop refeeding hypophosphatemia. A slow increment of caloric intake and even intentional reduction of caloric intake should be considered for treating refeeding hypophosphatemia.

\section{Discussion and conclusions}

In our case, the VT during HD was thought to be triggered by hypokalemia that resulted from intracellular shift by refeeding syndrome in addition to removal by $\mathrm{HD}$. Potential contribution of refeeding syndrome related to IDPN for the VT was considered based on the following two reasons. First, the serum phosphate concentration decreased substantially from 7.3 to $1.9 \mathrm{mg} / \mathrm{dL}$ during the HD session in which IDPN fluid was administered. It decreased from 6.1 to $2.2 \mathrm{mg} / \mathrm{dL}$ on his stable status despite nearly equal dialysis efficiency. The decline in serum phosphate during HD on the 10th day was higher than that on the usual HD session, even though the post-HD phosphate concentration does not meet the criteria of hypophosphatemia $(1.85 \mathrm{mg} / \mathrm{dL})$. In addition to removal by HD, intracellular shift of phosphate caused by high-calorie parenteral nutrition during the short period can contribute to a rapid decline of the serum phosphate concentration. Second, VT and QTc prolongation were cue findings prompting consideration of refeeding syndrome. Actually, QTc prolongation associated with HD depends in part on the concentration of potassium in the dialysate [20]. An earlier report described gradual lowering of the serum potassium concentration as preferred to prevent arrhythmia, rather than rapid lowering using dialysate with constant potassium concentration of $2.0 \mathrm{mEq} / \mathrm{L}$. In the present case, IDPN can contribute to the intracellular shift of potassium and can therefore accelerate hypokalemia during HD.

Negative potassium balance resulted from both fasting without supplementation and removal by HD might also contribute to cause the VT. When long-term fasting is required, essential elements including potassium, phosphorus, and magnesium should be given even for dialysis patients. In our case, although serum potassium level was within the normal range before the HD session, it falls into hypokalemic range during the HD on the 10th day of the admission. Timely supplementation of essential elements including adjusting potassium concentration in dialysate $(3.0-4.0 \mathrm{mEq} / \mathrm{L})$ may prevent refeeding syndrome.

We cannot completely exclude the possibility of "idiopathic" VT unrelated to IDPN and HD. However, because continuous ECG monitoring did not detect VT recurrence after supplementation of essential elements, it is reasonable to consider that the VT was triggered by electrolyte abnormalities such as hypokalemia and hypomagnesemia exacerbated by IDPN and HD.

On the 10th day of admission, our patient was categorized as being at high risk of developing refeeding syndrome because he had been supplied only approximately $100 \mathrm{kcal} /$ day for 10 days. Therefore, if our patient started to take a $10-\mathrm{kcal} / \mathrm{kg} /$ day nutrient supply, then the appropriate administration rate of IDPN would be $20-25 \mathrm{kcal} / \mathrm{h}$ based on the assumption that the nutritional supply per day was divided over $24 \mathrm{~h}$. However, the actual rate of IDPN was $240 \mathrm{kcal} / \mathrm{h}$, which was 10 times higher than the recommended amount. Based on the risk stratification of refeeding syndrome, total parenteral nutrition with a slow rate of calorie infusion, instead of IDPN, would be preferred, especially for patients ending a considerable period 
of fasting. If IDPN must be selected for such patients, its starting dose should be reduced.

In conclusion, we experienced a patient with refeeding syndrome accompanied with VT triggered by IDPN starting after starvation. When IDPN for malnourished HD patients is considered, the risk of refeeding syndrome should be fully assessed and managed before starting IDPN.

\section{Abbreviations}

AKI: Acute kidney injury; BC Renal Agency: The British Columbia Renal Agency; BMI: Body mass index; CKD: Chronic kidney disease; EBPG: European Best Practice Guidelines; ERA-EDTA: European Renal Association-European Dialysis and Transplant Association; HD: Hemodialysis; IBW: Ideal body weight; IDPN: Intradialytic parenteral nutrition; IrSPEN: The Irish Society for Clinical Nutrition and Metabolism; ISRNM: The International Society of Renal Nutrition and Metabolism; NICE: The National Institute for Health and Care Excellence; PEW: Protein-energy wasting; QTc: Corrected QT interval; SGA: Subjective global assessment; UBW: Usual body weight; VT: Ventricular tachycardia

\section{Acknowledgements}

The authors express their appreciation to the medical staff of the University of Tokyo Hospital, Tokyo, Japan, for collecting the samples from the patient and for analyzing them.

\section{Availability of data and materials}

All data and materials were included in the manuscript.

\section{Authors' contributions}

$\mathrm{YH}$ is responsible for the manuscript. $\mathrm{YH}$ and $\mathrm{YM}$ acquired the data, interpreted the data, drafted the manuscript, and revised it. $A M, K D$, and $M N$ helped to draft the manuscript. All authors read and approved the final manuscript.

\section{Ethics approval and consent to participate}

Written informed consent was obtained from the patient. For this type of case report, formal consent from a local ethics committee is not required.

\section{Consent for publication}

Written informed consent was obtained from the patient for the publication of this case report and any accompanying images.

\section{Competing interests}

The authors declare that they have no competing interests.

\section{Publisher's Note}

Springer Nature remains neutral with regard to jurisdictional claims in published maps and institutional affiliations.

\section{Author details}

${ }^{1}$ Department of Hemodialysis and Apheresis, The University of Tokyo Hospital, Tokyo, Japan. ${ }^{2}$ Division of Nephrology and Endocrinology, The University of Tokyo, Tokyo, Japan. ${ }^{3}$ Department of Acute Medicine, The University of Tokyo Hospital, Tokyo, Japan.

\section{Received: 5 March 2018 Accepted: 7 August 2018}

Published online: 19 September 2018

\section{References}

1. Mehanna HM, Moledina J, Travis J. Refeeding syndrome: what it is, and how to prevent and treat it. BMJ. 2008;336:1495-8.

2. Obeid $\mathrm{OA}$, Hachem DH, Ayoub JJ. Refeeding and metabolic syndromes: two sides of the same coin. Nutr Diabetes. 2014;4:e120.

3. De Silva A, Smith T, Stroud M. Attitudes to NICE guidance on refeeding syndrome. BMJ. 2008:337:a680.

4. Bossola M, Muscaritoli M, Tazza L, Giungi S, Tortorelli A, Rossi Fanelli F, Luciani G. Malnutrition in hemodialysis patients: what therapy? Am J Kidney Dis. 2005;46:371-86.
5. BC Renal Agency: Intradialytic Parenteral Nutrition (IDPN) [http://www bcrenalagency.ca/resource-gallery/Documents/Intradialytic Parenteral Nutrition (IDPN).pdf] Accessed 5 May 2018.

6. Fouque $D$, Vennegoor $M$, ter Wee $P$, Wanner $C$, Basci A, Canaud B, Haage $P$, Konner K, Kooman J, Martin-Malo A, et al. EBPG guideline on nutrition. Nephrol Dial Transplant. 2007;22 Suppl 2:i145-87.

7. Druml W, Kierdorf HP, Working group for developing the guidelines for parenteral nutrition of The German Association for Nutritional Medicine. Parenteral nutrition in patients with renal failure - Guidelines on Parenteral Nutrition, Chapter 17. Ger Med Sci. 2009;7:Doc11

8. Fouque D, Kalantar-Zadeh K, Kopple J, Cano N, Chauveau P, Cuppari L, Franch H, Guarnieri G, Ikizler TA, Kaysen G, et al. A proposed nomenclature and diagnostic criteria for protein-energy wasting in acute and chronic kidney disease. Kidney Int. 2008;73:391-8.

9. Cano NJ, Fouque D, Roth H, Aparicio M, Azar R, Canaud B, Chauveau P, Combe C, Laville M, Leverve XM, French Study Group for Nutrition in Dialysis. Intradialytic parenteral nutrition does not improve survival in malnourished hemodialysis patients: a 2-year multicenter, prospective, randomized study. J Am Soc Nephrol. 2007;18:2583-91.

10. Marsen TA, Beer J, Mann H, German IDPN-Trial group. Intradialytic parenteral nutrition in maintenance hemodialysis patients suffering from proteinenergy wasting. Results of a multicenter, open, prospective, randomized trial. Clin Nutr. 2017;36:107-17.

11. Stanga Z, Brunner A, Leuenberger M, Grimble RF, Shenkin A, Allison SP, Lobo DN. Nutrition in clinical practice-the refeeding syndrome: illustrative cases and guidelines for prevention and treatment. Eur J Clin Nutr. 2008;62:687-94.

12. Rio A, Whelan K, Goff L, Reidlinger DP, Smeeton N. Occurrence of refeeding syndrome in adults started on artificial nutrition support: prospective cohort study. BMJ Open. 2013;3

13. Doig GS, Simpson F, Heighes PT, Bellomo R, Chesher D, Caterson ID, Reade MC, Harrigan PW, FCICM for the Refeeding Syndrome Trial Investigators Group. Restricted versus continued standard caloric intake during the management of refeeding syndrome in critically ill adults: a randomised, parallel-group, multicentre, single-blind controlled trial. Lancet Respir Med. 2015;3:943-52.

14. Marik PE, Bedigian MK. Refeeding hypophosphatemia in critically ill patients in an intensive care unit. A prospective study. Arch Surg. 1996;131:1043-7.

15. The Irish Society for Clinical Nutrition and Metabolism (IrSPEN) : Prevention and treatment of refeeding syndrome in the acute care setting [http://www.irspen. ie/wp-content/uploads/2014/10//rSPEN_Guideline_Document_No1.pdf], Accessed 5 May 2018.

16. Brown CA, Sabel AL, Gaudiani JL, Mehler PS. Predictors of hypophosphatemia during refeeding of patients with severe anorexia nervosa. Int J Eat Disord. 2015;48:898-904

17. Pourhassan M, Cuvelier I, Gehrke I, Marburger C, Modreker MK, Volkert D, Willschrei HP, Wirth R. Prevalence of risk factors for the refeeding syndrome in older hospitalized patients. J Nutr Health Aging. 2018;22:321-7.

18. The National Institute for Health and Care Excellence (NICE): Nutrition support for adults oral nutrition support, enteral tube feeding and parenteral nutrition [https://www.nice.org.uk/guidance/cg32/evidence/fullguideline-194889853] Assessed 5 May 2018.

19. Genovesi S, Dossi C, Viganò MR, Galbiati E, Prolo F, Stella A, Stramba-Badiale M. Electrolyte concentration during haemodialysis and QT interval prolongation in uraemic patients. Europace. 2008;10:771-7.

20. Santoro A, Mancini E, London G, Mercadal L, Fessy H, Perrone B, Cagnoli L, Grandi E, Severi S, Cavalcanti S. Patients with complex arrhythmias during and after haemodialysis suffer from different regimens of potassium removal. Nephrol Dial Transplant. 2008;23:1415-21. 